\title{
A commentary on: "A 12-year population-based study of freezing of gait in Parkinson's disease"
}

\author{
Jacob J. Crouse ${ }^{1}$ and Ahmed A. Moustafa ${ }^{1,2 *}$ \\ ${ }^{1}$ School of Social Sciences and Psychology, University of Western Sydney, Sydney, NSW, Australia, ${ }^{2}$ Marcs Institute for Brain \\ and Behaviour, University of Western Sydney, Sydney, NSW, Australia
}

Keywords: Parkinson's disease, freezing of gait (FOG), dopamine

\section{A commentary on}

A 12-year population-based study of freezing of gait in Parkinson's disease by Forsaa, E. B., Larsen, J. P., Wentzel-Larsen, T., and Alves, G. (2015). Parkinsonism Relat. Disord. 21, 254-258. doi: 10.1016/j.parkreldis.2014.12.020

A recent study by Forsaa et al. (2015) details the prospective assessments of a population-based Parkinson's disease (PD) cohort, investigating the long-term progression and associated risk factors of freezing of gait (FOG). Building on previous work examining the progression of psychosis in PD (Forsaa et al., 2010), the authors followed a cohort of 232 PD patients, assessing both motor and non-motor disease features including FOG, severity of parkinsonism, motor complications, psychotic symptoms, and cognitive impairment at 4 and 8 years, and annually thereafter.

In this study, Forsaa et al. (2015) utilized a prospective longitudinal research design, allowing

\section{OPEN ACCESS}

Edited by:

P. Hemachandra Reddy, Texas Tech University, USA

Reviewed by:

Ramesh Kandimalla,

Texas Tech University, USA

Akhilesh K. Pandey,

Texas Tech University Health Sciences

Center, USA

${ }^{*}$ Correspondence:

Ahmed A. Moustafa, a.moustafa@uws.edu.au

Received: 27 March 2015 Accepted: 20 May 2015

Published: 02 June 2015

Citation:

Crouse JJ and Moustafa AA (2015) A commentary on: "A 12-year population-based study of freezing of gait in Parkinson's disease".

Front. Aging Neurosci. 7:106. doi: 10.3389/fnagi.2015.00106 for investigating and predicting symptom progression. This predictive capability is of importance to intervention and therapy, as FOG is associated with reduced quality of life (Moore et al., 2007; Walton et al., 2015), increased risk of falls and subsequent medical complications (Bloem et al., 2004), caregiver-burden (Schrag et al., 2006), and self-initiated social isolation (Bloem et al., 2004).

Forsaa et al. (2015) suggest that many PD patients may develop FOG during their disease course. This finding aids in remediating a discrepancy in the "freezing" literature, in relation to the highly variable prevalence rates of FOG in PD patients, with past research reporting variable rates between 31 and 87\% (Hely et al., 2005; Macht et al., 2007; López et al., 2010; Auyeung et al., 2012; Perez-Lloret et al., 2014). Forsaa et al. (2015) report a FOG point prevalence rate of $25 \%$ at the commencement of the study, $75 \%$ at the 8 -year follow-up, and $63 \%$ at the end of the study. This variability in the literature may result from previous overreliance on cross-sectional research, as well as dropout rates stemming from non-PD related comorbidities and increased mortality in PD patients displaying FOG.

As shown by Forsaa et al's (2015) long-term prospective follow-up design, repeated assessments of disease features and the use of robust statistical analyses, including logistic regression models and generalized estimating equations, the risk factors and concomitant features of FOG were explored in isolation from one another. The analyses revealed a significant relationship between motor fluctuations and FOG, as non-"freezers" presenting with motor fluctuations at the commencement of the study had more than three times the likelihood of developing FOG during the 12-year follow-up period, as compared with patients without motor fluctuations at baseline. Interestingly, dyskinesias were associated with a statistically non-significant (but still greater than 60\%) reduced risk of incidence of FOG during follow-up, a finding that needs further confirmation, as suggested by Forsaa et al. (2015). 
Currently, complete understanding of the pathophysiology of dyskinesias and motor fluctuations remains elusive. However, both appear to be associated with the degree of dopamine depletion and the use of levodopa (L-Dopa) (Linazasoro, 2007; Calabresi et al., 2008; Antonini et al., 2010), with approximately $50-80 \%$ of PD patients who receive L-Dopa for more than 510 years developing such complications (Marsden and Parkes, 1977; Rajput et al., 2002). There is mounting evidence that such motor complications might be somewhat related to the short-half life of the drug, as well as its potential to induce pulsatile stimulation of dopamine receptors. Further, treatment strategies utilizing continuous stimulation of dopamine receptors often result in reduced motor complications (Olanow et al., 2004; Antonini et al., 2010). While more research needs to be conducted, Forsaa et al's (2015) results of differential risk for FOG between dyskinesias and motor fluctuation suggest that the two may affect the basal ganglia and other brain areas differently.

The pathophysiology of FOG has been suggested to involve both dopaminergic and nondopaminergic networks in cortical, subcortical and brainstem regions (Shine et al., 2011), as evidenced by experimental and neuroimaging studies investigating the triggering of freezing episodes by visual, cognitive, and attentional tasks, as well as other environmental cues (Yogev-Seligmann et al., 2008; Almeida and Lebold, 2010; Cowie et al., 2010, 2012; Snijders et al., 2010; Matar et al., 2014; Plotnik et al., 2014). In support of the above, Forsaa et al. (2015) found that the severity of postural instability and gait disturbances (PIGD), as well as psychotic symptoms, each of which are thought to relate to extrastriatal pathology (Williams-Gray et al., 2006;

\section{References}

Almeida, Q. J., and Lebold, C. A. (2010). Freezing of gait in Parkinson's disease: a perceptual cause for a motor impairment? J. Neurol. Neurosurg. Psychiatry 81, 513-518. doi: 10.1136/jnnp.2008.160580

Antonini, A., Ursino, G., Calandrella, D., Bernardi, L., and Plebani, M. (2010). Continuous dopaminergic delivery in Parkinson's disease. J. Neurol. 257, 305-308. doi: 10.1007/s00415-010-5714-1

Auyeung, M., Tsoi, T. H., Mok, V., Cheung, C. M., Lee, C. N., Li, R., et al. (2012). Ten year survival and outcomes in a prospective cohort of new onset Chinese Parkinson's disease patients. J. Neurol. Neurosurg. Psychiatry 83, 607-611. doi: 10.1136/jnnp-2011-301590

Bloem, B. R., Hausdorff, J. M., Visser, J. E., and Giladi, N. (2004). Falls and freezing of gait in Parkinson's disease: a review of two interconnected, episodic phenomena. Mov. Disord. 19, 871-884. doi: 10.1002/mds. 20115

Calabresi, P., Di Filippo, M., Ghiglieri, V., and Picconi, B. (2008). Molecular mechanisms underlying levodopa-induced dyskinesia. Mov. Disord. 23, 570-579. doi: 10.1002/mds.22019

Cowie, D., Limousin, P., Peters, A., and Day, B. L. (2010). Insights into the neural control of locomotion from walking through doorways in Parkinson's disease. Neuropsychologia 48, 2750-2757. doi: 10.1016/j.neuropsychologia.2010. 05.022

Cowie, D., Limousin, P., Peters, A., Hariz, M., and Day, B. L. (2012). Doorwayprovoked freezing of gait in Parkinson's disease. Mov. Disord. 27, 492-499. doi: $10.1002 / \mathrm{mds} .23990$

Forsaa, E. B., Larsen, J. P., Wentzel-Larsen, T., and Alves, G. (2015). A 12-year population-based study of freezing of gait in Parkinson's disease. Parkinsonism Relat. Disord. 21, 254-258. doi: 10.1016/j.parkreldis.2014.12.020
Grimbergen et al., 2009), were independently associated with the occurrence of FOG during the 12-year study period.

Forsaa et al. identified several limitations to their research. First, the lack of neuropsychological data collected on subjects might have allowed for attentional dysfunctions and deficits in executive function to slip through unrecognized. Also, long intervals between follow-ups during the first eight years were identified as another limitation, one that was however remedied from the 8-year mark onward. During the initial 8 years, 136 subjects died, in which important data may have been missed. Another limitation is the authors' method of FOG assessment, which entailed utilizing a single item from the Unified Parkinson's Disease Rating Scale (UPDRS). This is limiting in that it is a fairly crude measure of "freezing," which may not allow for identifying of subtler aspects of gait. However, until recently, more expansive questionnaires detailing in-depth descriptions of FOG were unavailable (Nieuwboer et al., 2009), but the utility and sensitivity of the New Freezing of Gait Questionnaire is still an issue of contention (Shine et al., 2012).

Given the high frequency of FOG in the PD population and its inherent negative consequences, more research into the pathophysiology, treatment and prevention of this symptom is necessary. Forsaa et al. (2015) demonstrate the utility of a population-based, longitudinal design in understanding a progressive disease like $\mathrm{PD}$, offering new insights into potential predictive risk factors for FOG, and adds to the evidence-based conceptualization of PD not as the classical "disease of dopamine," but as a complex, multi-network, multineurotransmitter system disease.

Forsaa, E. B., Larsen, J. P., Wentzel-Larsen, T., Goetz, C. G., Stebbins, G. T., Aarsland, D., et al. (2010). A 12-year population-based study of psychosis in Parkinson disease. Arch. Neurol. 67, 996-1001. doi: 10.1001/archneurol.2010.166

Grimbergen, Y. A., Langston, J. W., Roos, R. A., and Bloem, B. R. (2009). Postural instability in Parkinson's disease: the adrenergic hypothesis and the locus coeruleus. Expert Rev. Neurother. 9, 279-290. doi: 10.1586/14737175.9.2.279

Hely, M. A., Morris, J. G., Reid, W. G., and Trafficante, R. (2005). Sydney multiceintre study of Parkinson's disease: non-L-dopa-responsive problems dominate at 15 years. Mov. Disord. 20, 190-199. doi: 10.1002/mds.20324

Linazasoro, G. (2007). Pathophysiology of motor complications in Parkinson disease: postsynaptic mechanisms are crucial. Arch. Neurol. 64, 137-140. doi: 10.1001/archneur.64.1.137

López, I. C., Ruiz, P. J., Del Pozo, S. V., and Bernardos, V. S. (2010). Motor complications in Parkinson's disease: ten year follow-up study. Mov. Disord. 25, 2735-2739. doi: 10.1002/mds.23219

Macht, M., Kaussner, Y., Möller, J. C., Stiasny-Kolster, K., Eggert, K. M., Krüger, H. P., et al. (2007). Predictors of freezing in Parkinson's disease: a survey of 6,620 patients. Mov. Disord. 22, 953-956. doi: 10.1002/mds.21458

Marsden, C. D., and Parkes, J. D. (1977). Success and problems of long-term levodopa therapy in Parkinson's disease. Lancet 1, 345-349. doi: 10.1016/S01406736(77)91146-1

Matar, E., Shine, J. M., Naismith, S. L., and Lewis, S. J. (2014). Virtual reality walking and dopamine: opening new doorways to understanding freezing of gait in Parkinson's disease. J. Neurol. Sci. 344, 182-185. doi: 10.1016/j.jns.2014.06.054

Moore, O., Peretz, C., and Giladi, N. (2007). Freezing of gait affects quality of life of peoples with Parkinson's disease beyond its relationships with mobility and gait. Mov. Disord. 22, 2192-2195. doi: 10.1002/mds.21659 
Nieuwboer, A., Rochester, L., Herman, T., Vandenberghe, W., Emil, G. E., Thomaes, T., et al. (2009). Reliability of the new freezing of gait questionnaire: agreement between patients with Parkinson's disease and their carers. Gait Posture 30, 459-463. doi: 10.1016/j.gaitpost.2009. 07.108

Olanow, C. W., Agid, Y., Mizuno, Y., Albanese, A., Bonuccelli, U., Damier, P., et al. (2004). Levodopa in the treatment of Parkinson's disease: current controversies. Mov. Disord. 19, 997-1005. doi: 10.1002/mds.20243

Perez-Lloret, S., Negre-Pages, L., Damier, P., Delval, A., Derkinderen, P., Destée, A., et al. (2014). Prevalence, determinants, and effect on quality of life of freezing of gait in Parkinson disease. JAMA Neurol. 71, 884-890. doi: 10.1001/jamaneurol.2014.753

Plotnik, M., Shema, S., Dorfman, M., Gazit, E., Brogzol, M., Giladi, N., et al. (2014). A motor learning-based intervention to ameliorate freezing of gait in subjects with Parkinson's disease. J. Neurol. 261, 1329-1339. doi: 10.1007/s00415-0147347-2

Rajput, A. H., Fenton, M. E., Birdi, S., Macaulay, R., George, D., Rozdilsky, B., et al. (2002). Clinical-pathological study of levodopa complications. Mov. Disord. 17, 289-296. doi: 10.1002/mds.10031

Schrag, A., Hovris, A., Morley, D., Quinn, N., and Jahanshahi, M. (2006). Caregiver burden in Parkinson's disease is closely associated with psychiatric symptoms, falls, and disability. Parkinsonism Relat. Disord. 12, 35-41. doi: 10.1016/j.parkreldis.2005.06.011

Shine, J. M., Moore, S. T., Bolitho, S. J., Morris, T. R., Dilda, V., Naismith, S. L., et al. (2012). Assessing the utility of freezing of gait questionnaires in Parkinson's disease. Parkinsonism Relat. Disord. 18, 25-29. doi: 10.1016/j.parkreldis.2011.08.002
Shine, J. M., Naismith, S. L., and Lewis, S. J. (2011). The pathophysiological mechanisms underlying freezing of gait in Parkinson's disease. J. Clin. Neurosci. 18, 1154-1157. doi: 10.1016/j.jocn.2011.02.007

Snijders, A. H., Weerdesteyn, V., Hagen, Y. J., Duysens, J., Giladi, N., and Bloem, B. R. (2010). Obstacle avoidance to elicit freezing of gait during treadmill walking. Mov. Disord. 25, 57-63. doi: 10.1002/mds.22894

Walton, C. C., Shine, J. M., Hall, J. M., O’Callaghan, C., Mowszowski, L., Gilat, M., et al. (2015). The major impact of freezing of gait on quality of life in Parkinson's disease. J. Neurol. 262, 108-115. doi: 10.1007/s00415-014-7524-3

Williams-Gray, C. H., Foltynie, T., Lewis, S. J., and Barker, R. A. (2006). Cognitive deficits and psychosis in Parkinson's disease: a review of pathophysiology and therapeutic options. CNS Drugs 20, 477-505. doi: 10.2165/00023210200620060-00004

Yogev-Seligmann, G., Hausdorff, J. M., and Giladi, N. (2008). The role of executive function and attention in gait. Mov. Disord. 23, 329-342. doi: $10.1002 / \mathrm{mds} .21720$

Conflict of Interest Statement: The authors declare that the research was conducted in the absence of any commercial or financial relationships that could be construed as a potential conflict of interest.

Copyright (c) 2015 Crouse and Moustafa. This is an open-access article distributed under the terms of the Creative Commons Attribution License (CC BY). The use, distribution or reproduction in other forums is permitted, provided the original author(s) or licensor are credited and that the original publication in this journal is cited, in accordance with accepted academic practice. No use, distribution or reproduction is permitted which does not comply with these terms. 